\title{
MARCAS DA 'SANTA DICA' NAS PAISAGENS DE FESTAS EM LAGOLÂNDIA, GO
}

\author{
João Guilherme da Trindade Curado (UFG) \\ Carlos Eduardo Santos Maia (UFJF)
}

Lagolândia é distrito da goiana Pirenópolis, da qual dista $37 \mathrm{~km}$, sendo sete por estrada de chão, recoberta por poeira ou atoleiros, de acordo com as estações do cerrado: tempo das águas e tempo da seca. A pequena comunidade se amplia diante das festas - responsáveis por alterações na paisagem local.

RELIGIOSIDADE, FESTAS POPULARES, PAISAGEM, LAGOLÂNDIA. 
O povoado de Nossa Senhora da Conceição, hoje Lagolândia, originou-se na Fazenda Mozondó, na época da construção de uma pequena capela em madeira e palha. À frente dessa improvisada ermida foi aberto um grande largo e, do lado oposto à capela, situava-se a casa em que Dona Isabel Borges, viúva e proprietária das terras, passou o resto de seus dias criando a neta Benedita Cipriano Gomes, a Dica, junto com a filha Leocárdia, solteirona que se tornou madrinha da sobrinha e de quem passou a cuidar, hábito comum então na cultura rural.

1 Existem inúmeros relatos desses fatos, entre eles aqueles feitos por Curado (2009) e também o Processo Crime $n$. 651 (maço 9. Cartório do Crime de Pirenópolis. Pirenópolis, 1925) movido contra Dica, acusando-a de charlatã e embusteira.

2 As "enfermeiras do SaIão" não possuíam qualquer formação na área de saúde, atuavam como auxiliares nos trabalhos espirituais realizados por Dica.

3 A trajetória de Benedita Cipriano Gomes, Dica, foi traçada por Vasconcellos (1991) e Brito (1992), entre outros, já que essa líder teve intensa atividade política, participando das revoluções de 1930 e 1932, assim como da Coluna Prestes em 1925 (TELLES, 2008). Foi banida de Goiás, denunciada como mandante de crimes e teve um dos filhos assassinado (1953), o que a fez mudar de Lagolândia para Goiânia nesse ano.
Entre a infância e a adolescência, Dica passou a se diferenciar das demais crianças, como relatam os antigos moradores, que perceberam seus "dons", como o de se comunicar com o "outro mundo" e de realizar "curas" pelo contato de suas mãos, começando posteriormente a receitar beberagens "milagrosas". ${ }^{1}$ Tais práticas aconteciam na residência da família, que recebeu a denominação de "Salão de Cura", ou simplesmente Salão, e Dica contava com o apoio de mulheres da comunidade que a ajudavam em tais execuções, sendo essas voluntárias conhecidas como "enfermeiras". 2

Ao passo que cresciam Dica e sua fama, ${ }^{3}$ outras casas foram surgindo de frente para o nascente, seguindo o padrão de construção colonial com fachadas similares, porém diferenciando-se uma da outra pela coloração do madeirame; já que eram todas caiadas, cobertas por telhas de estilo colonial - capa e canal - e com quatro águas. Essas construções eram habitadas em momentos de festas, pois as residências rotineiras continuavam sendo as sedes das fazendas nas redondezas. O povoado tem seu nome alterado para Lagoa na metade da década de 1920, em referência a uma porção de água estagnada que se formava em um dos meandros do Rio do Peixe, próximo à qual se edificaram as primeiras casas e a improvisada capela. As moradias iniciais, além de estarem aglomeradas em um só lado do referido largo, eram edificações bastante semelhantes entre si e ali se recebiam as pessoas da comunidade, juntamente com os poucos visitantes, durante as festas religiosas, principalmente - como pode ser observado na Figura 1.

Datadas a partir das décadas iniciais do século $X X$, as festas em Lagolândia foram estabelecendo elos com a comunidade, o que fez com que as manifestações se tornassem essenciais para a manutenção da vida daquele grupo, que não se contentou em seguir o calendário básico das festividades implantado pela Igreja. Pelo contrário, a grande fé e as diferentes devoções fizeram com que muitos santos e santas fossem homenageados, destacando-se Nossa Senhora da Conceição e Nossa 


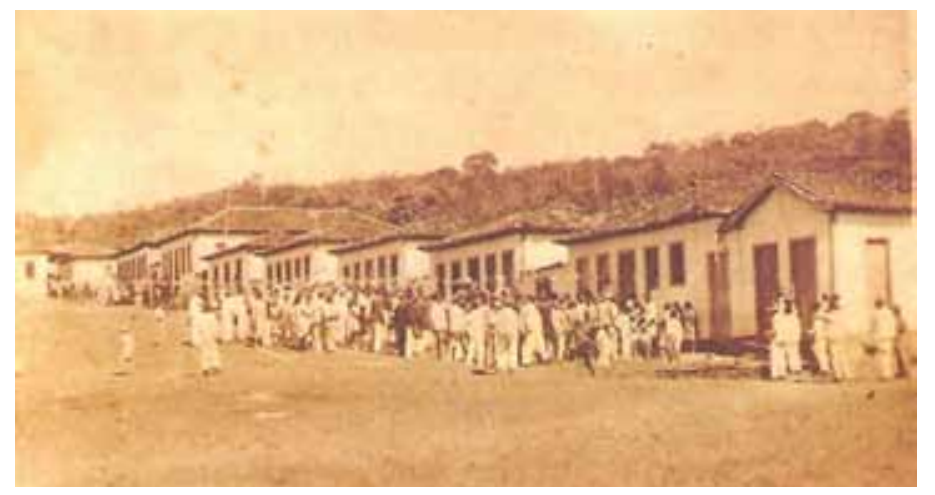

Figura 1: Conjunto inicial das casas de Lagolândia durante uma festa Foto: Reprodução de Rezende, 2009, p. 85

Senhora do Livramento, para as quais se construíram oragos. O hibridismo religioso local, porém, é amplo e, por volta de 1980, foi instalado no distrito um templo da Assembleia de Deus que conta atualmente com pouco mais de dez fiéis naquela localidade.

Há festas que passaram por interrupções e foram retomadas, como, por exemplo, o terço de Santa Luzia, cuja responsabilidade cabia a Norbeta Grisaste Pereira, uma das "enfermeiras" do Salão, que enviava carta a Dica quando esta residia em Goiânia desde o assassinato de seu filho Pedro, em 1953:

e aqui vai esse dinheiro, o resto do leilão de Santa Luzia, vai $790 \mathrm{Cr}$ \$ setesentos e noventa cruzeiros, que é para a senhora trocar minha Santa Luzia, não esquecer porque os dias já estão muito pouco para o dia da minha resa por isso peço a senhora não esquecer de comprar minha Santa Luzia. ${ }^{4}$

A carta, redigida em 22 de novembro de 1966, indica que a tradição das festas em Lagolândia possui respeitável organização, pois o dinheiro do leilão realizado no ano anterior fora guardado para a compra de uma nova imagem para a festa de 1966, que seria abrilhantada pela presença de Dica, que, tendo oportunidade, visitava Lagolândia. A correspondência, ao consignar os preparativos para a festa, deixa entrever mudanças na geografia lagolandense, ainda que de modo sutil. Isso pode ser inferido em trecho dessa mesma carta, quando a fiel "enfermeira" e amiga a alerta sobre os preparativos que estão sendo tramados para a festa do Divino Pai Eterno, que aconteceria em juIho do ano seguinte: "Madrinha Dica eu estou mandando notícias de todos mais eu tenho pressa que a senhora vinha por motivo que não posso lhe contar em carta, eu estou tão encomodada e com pressa que a senhora venha". ${ }^{5}$

Fato é que políticos de Pirenópolis, ligados até mesmo à oposição, estavam organizando a festa, sendo que um deles tinha sido sorteado Imperador. ${ }^{6}$ A situação em Lagolândia mostrava-se crítica, pois estava em tramitação, naquele momento, um

4 Carta de Norbeta a Dica, 22.11.1966, p. 3.

5 Carta de Norbeta a Dica, 22.11.1966, p. 2.

6 Imperador ou festeiro é a denominação atribuída ao condutor da festa, a pessoa que simbolicamente é o organizador, possuindo assim lugar de destaque nos momentos festivos, e o único com direito a portar coroa. Em Lagolândia, na Festa do Divino Pai Eterno há também a Rainha de Nossa Senhora do Rosário e o Rei de São Benedito, que dividem com o Imperador as honras e despesas da festa. 
processo que daria fim ao município, o que ocorreu em 10 de outubro de 1967. Essas informações locais eram encaminhadas a Dica por carta, sendo alguns assuntos evitados, o que nos leva a inferir que, mesmo distante, ela influenciava o posicionamento dos habi-

7 Processo s/n., maço 41, 1953, p. 22.

8 o conceito de paisagem aqui abordado está de acordo com Santos (1997, p. 61): "tudo aquilo que nós vemos, o que nossa visão alcança, é a paisagem. Esta pode ser definida como o domínio do visível, aquilo que $a$ vista abarca. Não é formada apenas de volume, mas também de cores, movimentos, odores $e$ sons etc.", bem como com Mendonza et al. (1982, p. 132): "a paisagem é em grande parte uma composição mental resultante de uma seleção e estruturação subjetiva a partir da informação emitida pelo entorno, mediante a qual este se faz compreensivel ao homem e orienta suas decisões $e$ comportamento". tantes sobre tais querelas. Era Dica, em Goiânia, quem provavelmente lia as cartas, visto que, tida como analfabeta na infância e juventude, aprendeu a ler e a escrever no transcorrer da vida, como constatado em processo de 1953, quando foi caracterizada como "doméstica, alfabetizada, residente em Lagolândia".?

Recentemente, uma moradora do povoado retomou essa tradição de reza do terço a Santa Luzia e, como no passado, existem anotações em cadernos sobre as doações/contribuições realizadas pelos fiéis. A prática foi observada em relação a outras festas e traz não a discriminação das prendas a serem leiloadas, mas sim os valores e quem as arrematou, notando-se recorrência de arrematadores por festa, exceto no último dia de novena, quando o fluxo de pessoas de outras localidades é maior, em especial por ocasião da festa do Divino Pai Eterno - realizada em meados de julho.

As rezas de terços a santos de devoção da família são uma constante em Lagolândia. Alguns desses terços realizam-se por ocasião de aniversários natalícios ou de casamentos, indicando a necessidade de a comunidade se reunir em torno de comemorações. Atualmente se mantém a tradição herdada de Dica, que estabeleceu a reza do terço às $18 \mathrm{~h}$ no Salão, ou na Igreja da Imaculada Conceição - quando realizada na igreja, o sino toca uma hora antes para que todos possam se preparar, havendo assim seu alarde pela sonoridade dada na paisagem. ${ }^{8}$ Quando ocorre no Salão, as pessoas se deslocam para lá provocando um pequeno movimento pelo distrito, além de cantar e fazer orações junto ao túmulo de Dica, que se localiza em frente ao Salão.

Os terços são realizados nas casas em função de datas especiais, o que exige preparação mais cuidadosa: são feitos convites entre os moradores e queimados fogos, as pessoas se vestem com "roupas de festas" e o caráter da reza torna-se mais solene, pois está envolvida alguma comemoração de um dos integrantes da comunidade, ocorrendo também farta distribuição de comida e bebida entre os partícipes. O que caracteriza esse ritual, atualmente, muito mais do que a devoção é a necessidade de socialização do grupo em torno dos princípios estabelecidos por Dica - entre eles a festa e a fé, com suas referências na paisagem através dos sons, dos cheiros, cores, movimentos, símbolos, etc. Os convites em questão são feitos boca a boca entre os moradores locais; com os que se mudaram para outras localidades, em especial para Goiânia acompanhando Dica, os três orelhões existentes no distrito são a via de comunicação, bem como os cartazes das fes- 
tas, que são produzidos com antecedência e distribuídos e encaminhados - em mãos - a membros da comunidade que não moram mais em Lagolândia.

Uma importante festa que voltou a ocorrer é realizada em morro próximo, em que foi reconstruída a capelinha aos Anjos da Guarda, em 2007, relembrando outra que ali existia desde 1925 - e que ruiu - na qual também se realizava a festa de São Pedro. O caminho até a igrejinha pode ser transposto pela estrada, o que aumenta a distância, ou por um trieiro, ${ }^{9}$ usado, entre outras práticas, na procissão de sua reinauguração, percorrendo as águas do Rio do Peixe. A organização da reconstrução coube a uma afilhada a quem, em sonho, Dica pediu que auxiliasse no reerguimento da capelinha. $A$ escolha do local se deveu ao fato de ser um dos pontos mais altos e, segundo informam os moradores, tinha a premissa de proteger Lagolândia, por isso Dica teria indicado aquela localidade, visível de todos os pontos de Lagolândia, confirmando outra marca de Dica na paisagem festiva do lugar em ponto estratégico (agora, no alto).

Existe também um grupo de mulheres que, por serem associadas, promovem e/ ou organizam grande parte dos festejos locais. A Associação Feminina da Imaculada Conceição existe desde os tempos de Dica, mas, com a morte da líder local, em 1970, foi enfraquecida. No final da década de 1980, contudo, revitalizou-se e chegou a contar com registro em cartório. Atualmente, substituiu-se a normatização do registro por um estatuto que guarda indicativos e premissas estabelecidos por Dica, como, por exemplo, a realização, a cada final de mês, de reuniões fechadas na sede administrativa que só as mulheres associadas podem freqüentar. São as mulheres as responsáveis pela manutenção da praça central construída no final da década de 1980 e motivo de seu orgulho.

Em pequenos povoados as praças, quando existem, são referências para pensar as relações de poder da comunidade; em Lagolândia são também marcas da atuação e do poder feminino. A construção da praça local se deu por pressão da Associação Feminina junto ao então prefeito de Pirenópolis. Não foram contratados arquitetos ou paisagistas, posto que as próprias associadas desenharam e orientaram os trabalhos. Os bancos espalhados pelos caminhos da praça levam os nomes das associadas e estão dispostos próximo aos canteiros por elas cuidados.

A manutenção da praça é responsabilidade das associadas e as que não mais residem no distrito encarregam as "comadres" de cuidar dos canteiros a elas pertencentes. A placa de inauguração relembra que a praça é obra da Associação Feminina da Imaculada Conceição, fundada por Dica. Na outra extremidade, há um busto da líder ladeado por dois anjos, figuras recorrentes no imaginário da comunidade e, por isso, presentes nas festas através de crianças que vestem camisolas com asas. Os canteiros da praça são em formato de coração, cálice, estrelas, lua e anjos.

A praça em Lagolândia, como paisagem (figuras 2 e 3), é apropriada nas festas servindo de ponto de encontros e local de parada das folias para rezas junto ao cruzeiro, localizado próximo ao busto de Dica. As associadas mantêm, cuidam, vigiam e guardam

CURADO, João Guilherme da Trindade e MAIA, Carlos Eduardo Santos. Marcas... 


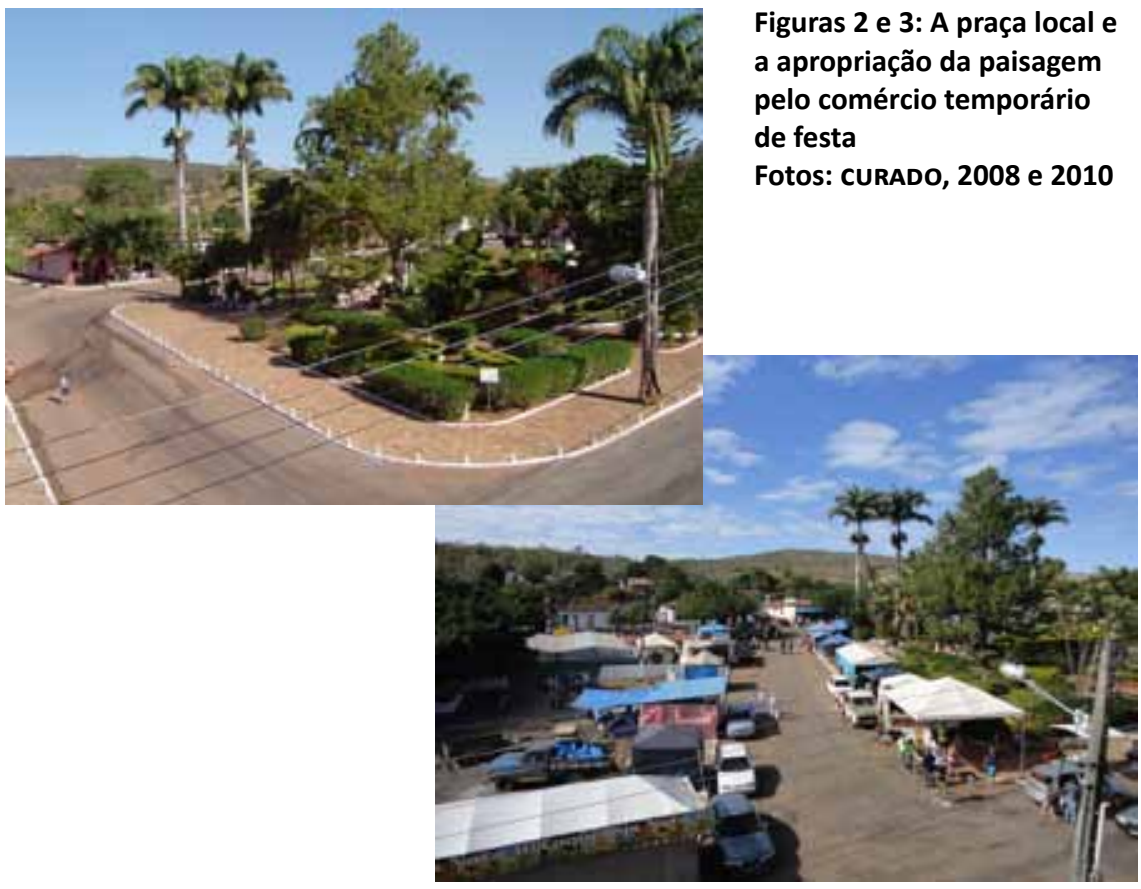

a praça como se fosse extensão de suas casas, tendo, aliás, autoridade de chamar atenção das pessoas que não mostram "comportamento apropriado" àquele local. Sua centralidade na paisagem do vilarejo demarca, assim, o poder feminino que ali impera, desde a época de Dica.

A Associação da Imaculada Conceição possui sede própria que se encontra perto do local em que hoje há ruínas do que foi uma "usina de luz", como é conhecido esse ponto pela comunidade. Mais precisamente, a usina localiza-se nas imediações do Córrego Lages, que denominou uma grande fazenda que agora empresta seu nome ao que chamam de "região". Empreendimento realizado pela parceria de membros da família Moreira, a usina gerou energia elétrica para Lagolândia nas década de 1940 e 1950 . Os moradores mais antigos contam que a luz era um "fiapinho de nada", mas que possibilitava o diminuir da noite. A luz era fornecida até as 21 horas, após o que voltavam a usar as lamparinas. A energia elétrica estatal só chegou ao distrito em 1982 (REZENDE, 2009, p. 98), uma década após o falecimento de Dica, que inaugurou a antiga "usina" com uma festa, expressando sua marca em paisagem composta no momento de festas não religiosas, o que reitera seu amplo poder de liderança. Antes, segundo uma moradora de Lagolândia,

não tinha luz! As luminárias eram assim... Na rua, as mulheres faziam, ela [Dica] ordenava 'faz azeite!' e as mulheres faziam azeite e punha na laranja. Pegava a laranja, cortava ao meio, tirava a polpa, assim, e enchia de azeite e fazia um pavio, torcia o cordão e aí põe dentro encharcado e risca o fogo, daí fazia lamparina, as luminárias da rua, cada lugar tinha uma estaquinha assim, 
um pauzinho de bambu, ou uma varinha do mato e punha a laranja. Ficava bonito, daqui e ali pra iluminar para a procissão passar. Eu lembro que eu ajudei muita a fazer isso, e eu era pequena ainda, mas eu já fazia! Isso aturou muitos anos, depois que veio energia pra cá que largou disso, que deixou de fazer de10 Moreira, entrevista pois que veio o progresso, mas era bom. ${ }^{10}$ realizada em 20.07.2009.

Ao relembrar-se da iluminação para homenagear os santos em procissão, a entrevistada apontou ainda peculiaridades ligadas à paisagem local. Em sua constituição como palco, há na paisagem um percurso festivo recorrente nos cortejos da festa do Divino Pai Eterno, relacionando-se também aos demais circuitos festivos que acontecem em Lagolândia: passa-se sempre pelo Salão, mesmo depois do falecimento de Dica - clara homenagem à líder local.

Sendo assim, a paisagem desses trechos pode ser compreendida como constituinte dos momentos festivos, que mantêm relações espaçotemporais distintas, mas que se interpenetram. Assim,

muitas questões podem ser levantadas sobre as características de uma paisagem: o que é antigo e o que é recente? O que é típico e o que é excepcional? O que é acidental e o que é intencional? O que é transitório e o que é permanente? O que foi imposto pelo homem e o que foi dado pela natureza?

Essas questões marcam o caminho para se compreender um modo de vida e para a compreensão de alguns processos de mudança geográfica. As respostas (ou respostas parciais) a tais perguntas são decifradas a partir da evidência fragmentária embutida na paisagem (WAGNER e MIKESELL, 2003, p. 37).

Semelhantes observações podem e devem ser consideradas em relação à Lagolândia, que passou por vários estádios desde sua consolidação inicial como povoado, ou mesmo com as alterações que ocorrem em momentos de festas implantadas por Dica - e mantidas também na intencionalidade de homenageá-la -, diferenciando-se das paisagens cotidianas, como demonstram dois momentos distintos tendo o Salão por referência nas figuras 4 e 5 .

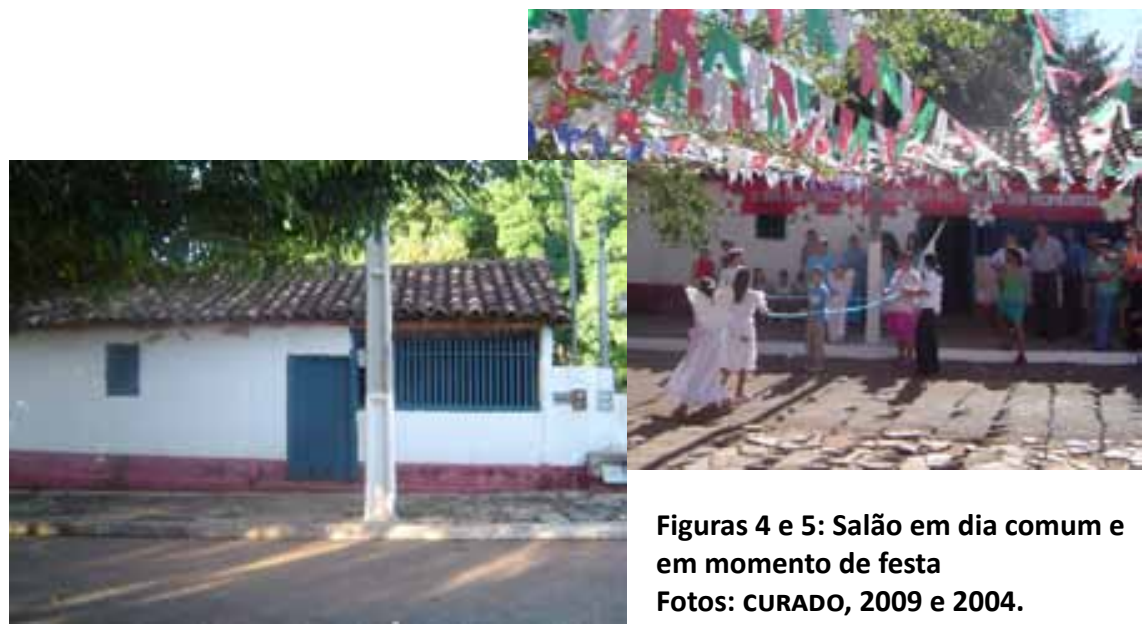

CURADO, João Guilherme da Trindade e MAIA, Carlos Eduardo Santos. Marcas... 


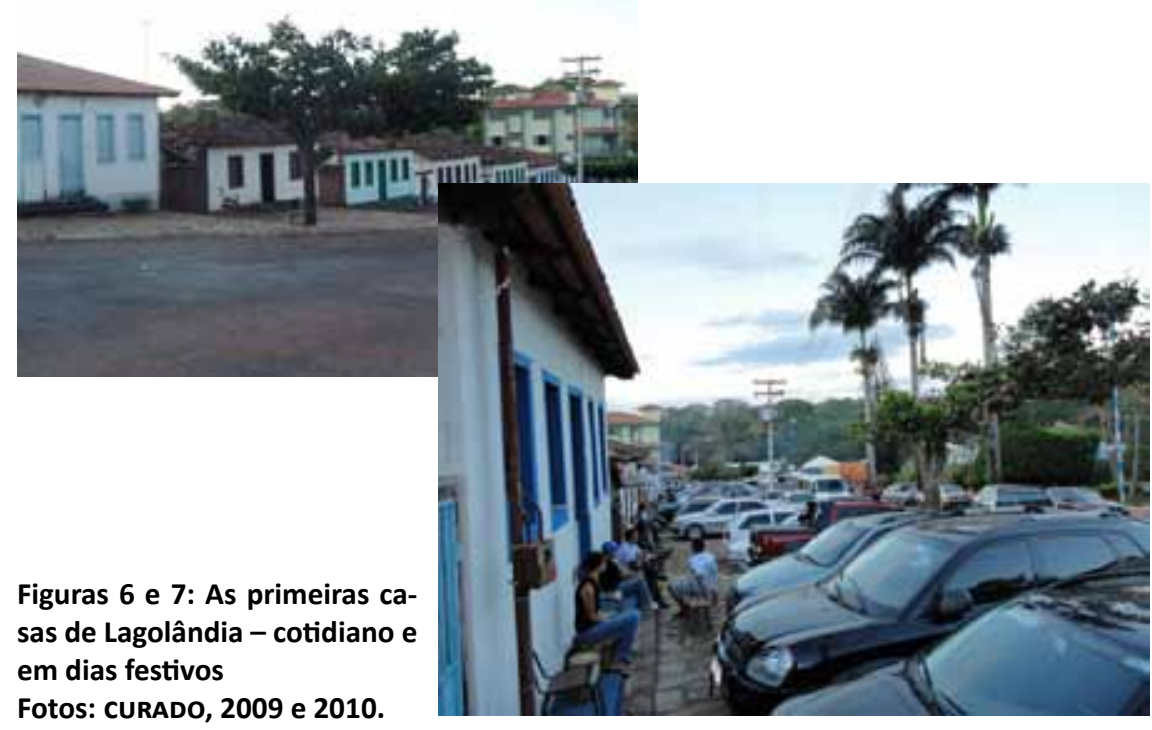

Nota-se, nas fotos, que há "evidências fragmentárias" de elementos da paisagem que nos levam a questionar o que é transitório e permanente, antigo e moderno, típico e excepcional, intencional e acidental a partir de um motivo, a festa, e de um modo de vida que, como temos procurado expor, rememora nas festas sua principal líder, Benedita Cipriano Gomes, a Dica.

Entre novembro de 1963 e outubro de 1967 transita o processo de emancipação de Lagolândia, que, entretanto volta a ser subordinada a Pirenópolis após a "queda" da emancipação, fato que deixa Dica ainda mais descontente e que foi questão preponderante para que grande parte dos habitantes, insatisfeitos com a situação, migrasse para Goiânia, só retornando ao distrito por ocasião das festas.

Voltar ao local de origem em datas festivas caracteriza prática comum que se mostra importante pelo fato de que "retornar para a festa é deixar-se levar pelos caminhos da emoção" (MAIA, 2001, p. 183), quando se reencontram parentes, amigos e paisagens familiares. Paralelamente, isso possibilita manter vínculos com a antiga moradia, abrindo-nos à perspectiva de uma "topoanálise" que "seria então o estudo psicológico sistemático dos locais de nossa vida íntima. Nesse teatro do passado, que é a memória, o cenário mantém os personagens em seu papel dominante" (BACHELARD, 1993, p. 28), e não se pode negar ainda hoje a dominância memorial de Dica, especialmente na conformação dos elementos das paisagens festivas. Tal fato, entretanto, também pode ser verificado pelos sentimentos que os lagolandenses parecem cultivar para com suas casas, de moradia ou de família, onde passaram a infância, pois 
na vida do homem, a casa afasta contingências, multiplica seus conselhos de continuidade. Sem ela, o homem seria um ser disperso. Ela mantém o homem através das tempestades do céu e das tempestades da vida. É o corpo e é alma. É o primeiro mundo do ser humano. Antes de ser 'jogado no mundo', como o professam as metafísicas apressadas, o homem é colocado no berço da casa. E sempre, nos nossos devaneios, ela é um grande berço (...) O ser é imediatamente um valor. A vida começa bem, começa fechada, protegida, agasalhada no regaço da casa (BACHELARD, 1993, p. 26).

A proteção, segundo os lagolandenses, advém não só das relações físicas com as casas em que viveram, mas ainda pela condição de que todos são conhecidos e é quase nula a incidência atual de novos moradores. Além disso, a figura de Dica comanda a comunidade com os ensinamentos, práticas e festas perpassadas pelas gerações.

As relações com o passado são marcantes, e alguns símbolos se fazem presentes e necessários para o cotidiano local, como o Cruzeiro, situado à frente da Igreja de Nossa Senhora da Conceição, e o túmulo de Dica, em localização oposta ao largo, que passou a representar um local diferente do que normalmente representa uma sepultura. O túmulo recebe visitas e, por abrigar as gameleiras, símbolos de destaque no imaginário lagolandense, é lugar de reflexão e, mesmo, de abrigo do sereno durante as alvoradas, ou do sol, durante o dia, particularmente quando há festa no Salão de Cura, onde Dica ficava a maior parte do dia enquanto morou em Lagolândia.

Considerando o fato de que "os geógrafos se interessam particularmente pela identidade dos lugares e pelos papéis que eles desempenham na formação de consciências individuais e coletivas" (BOSSÉ, 2004, p. 158), não se pode relegar a Lagolândia a representatividade das festas realizadas no distrito (como a festa de Nossa Senhora da Conceição, folia de reis, folia de São João e festa do Divino Pai Eterno, entre várias outras que também compõem o extenso calendário anual de festas implantado por Dica e mantido pela Associação Feminina e pela comunidade em geral) na compreensão dessa identidade; distrito que, tendo pouco mais de 500 habitantes, conta com grande incremento da população flutuante durante as festividades, em especial nas que ocorrem por ocasião das férias e feriados nacionais, independente das condições das estradas, como se pode notar nas figuras 6 e 7. Na primeira, a foto tirada em 20 de junho de 2009 apresenta uma situação "rotineira". Na segunda, a fotografia de 17 de julho de 2010 mostra a concorrência de pessoas vindas de outras localidades para a festa do Divino Pai Eterno.

Outra importante característica é o fato de a coletividade lagolandense possuir grande vínculo com a natureza, manifestada explicitamente no Rio do Peixe, que contorna parte do distrito e é considerado ente importante para a vida e para a história locais. O rio trouxe os habitantes, que procuraram e encontraram ouro, além de fornecer alimento em abundância, o que acabou por designar sua biotoponímia: Rio do Peixe (SEEMANN, 2003). Era nas águas do rio, denominado ainda de Rio Jordão, que se realizavam batizados, estreitando os laços de compadrio existentes na comunidade; por isso os termos "compadre" e "comadre" substituem os nomes de grande parte dos interlocutores. Era desse rio também que Dica retirava elementos utilizados para cura, como pedras e, 
mormente, água, em que diluía folhas e raízes que ministrava às pessoas que a procuravam para tratamentos.

O Rio do Peixe, com suas águas verdes, era utilizado pela comunidade nas proximidades do Salão para batizados conduzidos por Dica, prática que se mantém, nas noites de São João, ainda que não reconhecida pela Igreja. Já outra área, denominada "poção", onde deságua o Córrego Lages, é assaz frequentada por moradores para banhos e para a lavagem de roupas; além disso, durante a festa do Divino Pai Eterno, é montado um bar temporário que fica lotado durante as tardes em que não há cerimônias festivas. A maioria da população busca ali a água para consumo diário.

Lagolândia está bem próximo do Rio do Peixe, curso d'água considerado sagrado por Dica e por isso mesmo bastante respeitado pela comunidade, propiciando, portanto, contatos mais intensos entre a população e as águas que a cercam. Sobre as relações entre águas e homens, Dardel $(1952,29)$ apontou que

o fluido é cúmplice dos desenhos do homem. Por sua mobilidade, marcada pelo ritmo galopante da torrente ou movimento das ondas, a água exerce sobre o homem uma atração que algumas vezes beira o fascínio.

É sabido que o elemento água exerce deslumbramento nos seres humanos, em especial quando expressam sua ligação e gratidão com os cursos líquidos que perpassam suas vidas também em momentos festivos. Por isso, os rios são incorporados em sua fluidez em determinadas paisagens festivas, como naquelas de Lagolândia, onde possibilitam que gerações posteriores, distantes no tempo, revivam marcas de uma forte personalidade, como a de Dica, que se utilizou do Rio do Peixe para trazer "nova vida" à comunidade lagolandense. Dica, assim como o Rio do Peixe, segue sua trajetória meandrando as memórias nas festas lagolandenses, marcando suas paisagens no cerrado, delimitando caminhos, contornando o vilarejo e interligando natureza e cultura naquele povoado.

\section{REFERÊNCIAS BIBLIOGRÁFICAS}

BACHELARD, Gaston. A poética do espaço. Trad. Antonio de Pádua Danesi. São Paulo: Martins Fontes, 1993.

BOSSÉ, Mathias Le. As questões de identidade em geografia cultural - algumas concepções contemporâneas. In: CORRÊA, Roberto Lobato; ROSENDAHL, Zeny (Orgs.). Paisagens, textos e identidades. Rio de Janeiro: EdUERJ, 2004, p. 157-179.

BRITO, Eleonora Zicari Costa de. A construção de uma marginalidade através do discurso e da imagem: Santa Dica e a Corte dos Anjos Goiás - 1923 a 1925. Brasília: UnB, 1992. (Mestrado em História).

CARTA de Norbeta a Dica, 22. nov. 1966.

CURADO, João Guilherme da Trindade. Dica que cura. In: Anais do XI Simpósio Nacional da Associação Brasileira de História das Religiões - Sociabilidades religiosas: mitos, ritos e identidades. Goiânia: Ed. UCG, 2009, p. 1-10.

DARDEL, Eric. L' Homme et la Terre. Paris: Presses Universitaires de France, 1952.

MENDONZA, Josefina Gómez; JIMÉNEZ, Julio Muños y CANTERO, Nicolás Ortega. El pensamiento geográfico (Estudio interpretativo y antología de textos-de Humboldt e las tendencias radicales). 2a ed. Madri: Alianza Editorial, 1982, p. 48-154. 
MAIA, Carlos Eduardo Santos. O retorno para a festa e a transformação mágica do mundo: nos caminhos da emoção. In: ROSENDAHL, Zeny; CORRÊA, Roberto Lobato. Religião, identidade e território. Rio de Janeiro: EdUERJ, 2001, p. 177-199.

REZENDE, Waldetes Aparecida. Santa Dica: história e encantamentos. Goiânia: Ativa Gráfica \& Editora Ltda, 2009.

SANTOS, Milton. Metamorfose do espaço habitado. São Paulo: Hucitec, 1997.

SEEMANN, Jörn. A análise da toponímia como dimensão histórica na geografia cultural. In: Historical Dimensions of the relationship between space and culture. Rio de Janeiro: International Geographical Union. Commission on the Cultural Approach in Geography. Rio de Janeiro Conference, 10-12 june, 2003. 20p.

VASCONCELLOS, Lauro de. Santa Dica: encantamento do mundo ou coisa do povo. Goiânia: Cegraf/UFG, 1991. (Coleção Documentos Goianos, n. 22).

WAGNER, Philip L.; MIKESELL, Marvin W. Os temas da geografia cultural. In: CORRÊA, Roberto Lobato; ROSENDAHL, Zeny (Orgs.). Introdução à geografia cultural. Rio de Janeiro: Bertrand Brasil, 2003. p. 27-61.

João Guilherme da Trindade Curado é mestre e doutor em geografia pela Universidade Federal de Goiás e pesquisador de festas populares.

Carlos Eduardo Santos Maia é doutorado em geografia pela Universidade Federal do Rio de Janeiro e professor-associado I da Universidade Federal de Juiz de Fora. 